\title{
AGRADECIMENTOS EM ARTIGOS CIENTÍFICOS: percepção e comportamento dos pesquisadores brasileiros ${ }^{1}$
}

\author{
ACKNOWLEDGMENTS IN SCIENTIFIC PAPERS: \\ perceptions and behavior of Brazilian researchers
}

Gonzalo Rubén Alvarez²

Sônia Elisa Caregnato ${ }^{3}$

\begin{abstract}
RESUMO
A pesquisa explora, através de entrevistas, a percepção e o comportamento de agradecimento de pesquisadores de diferentes áreas do conhecimento filiados à Universidade Federal do Rio Grande do Sul (UFRGS) em artigos científicos. Os resultados mostram que os pesquisadores usam agradecimentos para recompensar contribuições menores de diversos tipos. As variáveis motivacionais identificadas no comportamento de agradecimento dos pesquisadores são determinadas por exigências institucionais (agradecimentos de natureza financeira) e por hábitos específicos (agradecimentos de natureza não financeira) das comunidades em cada área associados a uma questão ética e de conduta profissional. As evidências encontradas revelam comportamentos de agradecimento diferentes entre as áreas, com preferência de agradecimentos por apoio conceitual/intelectual em Ciências Sociais e Ciências Exatas e de agradecimentos por apoio técnico/instrumental em Ciências Agrárias e da Saúde. A ausência de regras formais impossibilitam a criação e aplicação de sanções para aqueles casos que omitem agradecer as contribuições recebidas. A maioria dos pesquisadores é contrária à utilização dos agradecimentos como indicador de impacto acadêmico. Conclui que a inclusão de agradecimentos em artigos para demonstrar gratidão aos pares e outros atores sociais é uma prática comum no processo de comunicação científica e pode exteriorizar formas não tradicionais de colaboração e influência material e/ou intelectual.
\end{abstract}

Palavras-chave: Agradecimentos. Pesquisa financiada. Colaboração. Ciência brasileira.

\begin{abstract}
The research work explores, through interviews, perceptions and behavior of researchers from different areas affiliated to the Universidade Federal do Rio Grande do Sul, Brazil (UFRGS) related to acknowledgments in scientific papers. The results show that researchers use acknowledgments to reward minor contributions of various types. The reasons for acknowledging identified in researchers' behavior are determined by institutional requirements (funding acknowledgments) and specific habits (acknowledgments of non-financial nature) of the communities in each area associated with ethical and professional rules of conduct. The evidence found reveals different acknowledgment behavior across areas of knowledge, with a preference for gratitude for conceptual / intellectual support in Social Sciences and Exact Sciences and gratitude for technical / instrumental support in Agriculture and Health Sciences. The lack of formal rules makes application of sanctions impossible for those cases in which authors fail to acknowledge the contributions received. Most researchers oppose the use of acknowledgments as an indicator of academic impact. The paper concludes that the inclusion of acknowledgments in articles to show gratitude to peers and other social actors is a common practice in the scientific communication process and can express non-traditional forms of collaboration and material and /or intellectual influence.
\end{abstract}

Keywords: Acknowledgments. Funded research. Collaboration. Brazilian Science.

Artigo submetido em 24/04/2020 e aceito para publicação em 02/09/2020

1 Artigo derivado da tese de doutorado "Práticas de agradecimento nos artigos científicos brasileiros indexados na Web of Science (2009-2016)" apresentada ao Programa de Pós-Graduação em Comunicação e Informação da Universidade Federal do Rio Grande do Sul (UFRGS).

2 Professor Adjunto do Departamento de Ciência da Informação Social. Universidade Federal Fluminense, Brasil. ORCID https://orcid. org/0000-0002-0677-5865. E-mail: gonzalorubenalvarez@gmail.com

3 Professora Titular do Departamento de Ciências da Informação. Universidade Federal do Rio Grande do Sul, Brasil. ORCID https:// orcid.org/0000-0002-5676-2763. E-mail: sonia.caregnato@ufrgs.br 


\section{INTRODUÇÃo}

Agradecimentos presentes em publicações científicas representam um fenômeno social e podem simbolizar a existência de vínculos colaborativos factuais eventualmente constituídos com colegas e outros atores sociais, trazendo à tona a importância das contribuições recebidas por aqueles que não adquirem o status de autor durante o desenvolvimento de uma pesquisa. Do mesmo modo que as citações, os agradecimentos possuem um significado social, cognitivo e instrumental (CRONIN; WEAVER, 1995), fornecendo indicadores de influência intelectual de mentores, tutores e conselheiros (CRONIN, 1991). Ao mesmo tempo, os agradecimentos são vistos como expressões de dívidas e gratidão, exibindo redes de relações, variedade de coletividades, conjunto de deveres e obrigações dentro do campo científico (BEN-ARI, 1987). 0 fato é que os agradecimentos no processo de comunicação científica podem retratar não apenas contribuições oriundas de discussões informais, feedback crítico de pares, avaliações de pareceristas ad-hoc, fornecimento de informações técnicas, entre outros, mas também contribuições de natureza financeira provenientes de incentivos e bolsas recebidas pelos pesquisadores através de projetos financiados.

Inseridos no campo de investigação da Sociologia da Ciência, estudos sobre práticas de agradecimento na comunicação científica começaram a ser desenvolvidos na década de 1970 (MACKINTOSH, 1972; PATEL, 1973), revelando formas de socialização baseadas em diferentes maneiras de organização e interação entre pesquisadores com pares e outros atores sociais. A partir da década de 1990, autores pioneiros no assunto focaram-se exclusivamente em análises de frequência e prevalência do tipo de apoio agradecido, propiciando a discussão teórica da prática de agradecimentos em termos de normativas, funções, significado e valores (CRONIN, 1991, 1995). Nos anos subsequentes, estudos bibliométricos sobre agradecimentos trouxeram importantes descobertas ao evidenciarem uma prevalência de manifestações de gratidão por apoio conceitual e/ou intelectual em revistas das Ciências Sociais e Humanidades (CRONIN; MCKENZIE; RUBIO, 1993), uma correlação positiva entre a frequência de agradecimentos e citações para indivíduos agradecidos em periódicos da Biblioteconomia e Ciência da Informação (CRONIN; MCKENZIE; STIFFLER, 1992) e uma discrepância de valores no que diz respeito ao número de menções por indivíduo agradecido (CRONIN; SHAW; LA BARRE, 2003).

Apesar de existirem vários estudos quantitativos, pesquisas qualitativas relacionadas com 0 significado social dos agradecimentos no processo de comunicação científica são ainda incipientes tanto no âmbito internacional quanto nacional. Inicialmente, 0 estudo das bases normativas do 
comportamento de agradecimento dos pesquisadores no âmbito das universidades norte-americanas demonstrou que, apesar de não existirem regras escritas, a prática dos agradecimentos é regida por um código implícito de conduta profissional (CRONIN; OVERFELT, 1994). Em nível de disciplina médica, abordagens qualitativas foram utilizadas para analisar os fatores motivacionais que estimulam 0 ato de agradecer dos pesquisadores brasileiros e colombianos da Imunologia, observando que a inclusão de agradecimentos em artigos para manifestar gratidão por contribuições cognitivas ou financeiras recebidas durante 0 andamento de uma investigação depende dos rituais próprios dos grupos (ROA CELIS, 2002). Em anos mais recentes, a avaliação qualitativa do comportamento dos pesquisadores venezuelanos e espanhóis da Biomedicina evidenciou que a inclusão de agradecimentos para pagar dívidas intelectuais difere de um cenário para outro e que as convenções comunicativas e socioculturais de contribuição acadêmica não são apenas dependentes da disciplina, mas também da linguagem e do contexto (SALAGER-MEYER; ARIZA; BERBESÍ, 2009). Em concordância com as descobertas de Cronin e Overfelt (1994), mediante levantamento das opiniões dos docentes de diferentes áreas da Universidade Federal de São Carlos (UFSCar) sobre a prática de ler e formular agradecimentos em publicações científicas, Hayashi (2018)confirma que os agradecimentos podem revelar as regras de engajamento que definem a dinâmica de colaboração e de interdependência entre pesquisadores.

Com base no contexto brasileiro de pesquisa, 0 aporte qualitativo deste estudo visa ampliar e reconstruir conhecimentos existentes sobre o significado social dos agradecimentos no processo de comunicação científica, explorando o comportamento de agradecimento de pesquisadores de diferentes áreas do conhecimento filiados à Universidade Federal do Rio Grande do Sul (UFRGS) enquanto autores de publicações. Embora presentes na literatura internacional, de modo geral, estudos sobre práticas de agradecimento não encontraram ainda espaço na agenda de pesquisa brasileira (HAYASHI; BELLO, 2014; HAYASHI, 2018). A realização de novas pesquisas qualitativas, analisando comportamentos individuais de agradecimento foi sugerida anteriormente na literatura, dado que ainda não há evidências empíricas consistentes que permitam legitimar o potencial valor que influências intelectuais têm via agradecimentos na ciência, em comparação com as citações (DÍAZ-FAES; BORDONS, 2017).

\section{PROCEDIMENTOS METODOLÓGICOS}

0 estudo qualitativo, de caráter exploratório, objetivou aprofundar a compreensão sobre 0 significado social dos agradecimentos em artigos no processo de comunicação científica. A partir 
da análise dos dados levantados através de entrevistas pessoais, explorou-se a percepção e 0 comportamento de agradecimento de um seleto grupo de pesquisadores de diferentes áreas filiados à UFRGS entre setembro e novembro de 2018.

Critérios específicos de seleção apontam para a boa colocação da UFRGS em rankings de avaliação universitários nacionais e internacionais. Em 2019, a instituição posicionou-se entre as cinco melhores universidades brasileiras (RANKING UNIVERSITÁRIO FOLHA, 2019) e entre as 500 melhores universidades do mundo (ACADEMIC RANKING OF WORLD UNIVERSITIES, 2017).

Os 12 entrevistados representam quatro grandesáreas do conhecimento (Quadro 1) eforam selecionados com base nos critérios de (i) conveniência (indivíduos que se encontravam próximos geograficamente e que aceitaram participar da pesquisa) e de (ii) produtividade, referente ao volume de artigos publicados por estes nas suas áreas, possibilitando a participação de pesquisadores mais experientes e com maior familiaridade com a prática de agradecimento por diferentes tipos de contribuições (intelectuais e/ou materiais) eventualmente recebidos ou ofertadas durante o curso de investigações que terminaram em publicação.

Quadro 1 - Pesquisadores entrevistados filiados à UFRGS por área

\begin{tabular}{|c|c|c|c|c|}
\hline Entrevistado & Sexo & Área & Unidade Acadêmica & Departamento \\
\hline 1 & M & \multirow{3}{*}{$\begin{array}{l}\text { Ciências Agrárias } \\
\text { (CAG) }\end{array}$} & \multirow{3}{*}{$\begin{array}{l}\text { Faculdade de } \\
\text { Agronomia }\end{array}$} & Solos \\
\hline 2 & M & & & $\begin{array}{c}\text { Horticultura e } \\
\text { Silvicultura }\end{array}$ \\
\hline 3 & $\mathrm{~F}$ & & & Fitossanidade \\
\hline 4 & M & \multirow{3}{*}{$\begin{array}{l}\text { Ciências Sociais } \\
\text { (CSO) }\end{array}$} & \multirow{3}{*}{$\begin{array}{c}\text { Faculdade de Ciências } \\
\text { Econômicas }\end{array}$} & \multirow{3}{*}{$\begin{array}{c}\text { Economia } \\
\text { e Relações } \\
\text { Internacionais }\end{array}$} \\
\hline 5 & M & & & \\
\hline 6 & M & & & \\
\hline 7 & M & \multirow{3}{*}{$\begin{array}{l}\text { Ciências Exatas } \\
\quad(\text { CEX) }\end{array}$} & \multirow{3}{*}{$\begin{array}{l}\text { Instituto de } \\
\text { Matemática e } \\
\text { Estatística }\end{array}$} & \multirow{3}{*}{$\begin{array}{c}\text { Matemática Pura e } \\
\text { Aplicada }\end{array}$} \\
\hline 8 & M & & & \\
\hline 9 & $F$ & & & \\
\hline 10 & M & \multirow{3}{*}{$\begin{array}{c}\text { Ciências da Saúde } \\
\text { (CSA) }\end{array}$} & \multirow{3}{*}{$\begin{array}{l}\text { Faculdade de Medicina } \\
\text { Hospital de Clínicas } \\
\text { Porto Alegre }\end{array}$} & $\begin{array}{l}\text { Medicina Interna } \\
\text { Serviço Oncologia }\end{array}$ \\
\hline 11 & $\mathrm{~F}$ & & & $\begin{array}{c}\text { Pediatria } \\
\text { Serviço } \\
\text { Hematologia }\end{array}$ \\
\hline 12 & $\mathrm{~F}$ & & & $\begin{array}{c}\text { Serviço } \\
\text { Hematologia }\end{array}$ \\
\hline
\end{tabular}

Fonte: Elaboração própria 
Apesar de terem sido analisadas apenas quatro áreas, a existência de variações entre elas nas práticas de comunicação científica propicia condições favoráveis para ampliar e reconstruir conhecimentos sobre o fenômeno social dos agradecimentos.

0 projeto de pesquisa foi encaminhado, através da Plataforma Brasil, para o Comitê de Ética em Pesquisa (CEP) da UFRGS. 0 parecer favorável final foi emitido sob o n² 2.845.693 em agosto de 2018. Com base no parecer do CEP, foi enviado por e-mail um convite formal para os pesquisadores selecionados para participar das entrevistas, junto com o Termo de Consentimento Livre e Esclarecido (TCLE), apresentando 0 tema central da investigação. Os pesquisadores voluntários que aceitaram participar da entrevista entregaram o TCLE devidamente assinado, incluindo a autorização para gravação dos depoimentos.

Todos os registros resultantes (gravações, transcrições, arquivos de computador) e trechos citados das entrevistas foram anonimizados através de um código alfanumérico, atribuindo a sigla da área do conhecimento (p. ex. "CAG" para Ciências Agrárias) seguido de um número identificador ( $p$. ex. "CAG1"), de forma a preservar a identidade e respeitar a confiança dos participantes da pesquisa. 0 instrumento empregado para a coleta dos depoimentos foi baseado em um roteiro com uma série de perguntas, divididas em nove blocos, elaborado com apoio de investigações anteriores sobre práticas de agradecimento envolvendo abordagens qualitativas (CRONIN; OVERFELT, 1994; ROA CELIS, 2002).

Após a transcrição das entrevistas, a etapa final incluiu a análise do conteúdo das falas dos entrevistados e a organização das informações coletadas por categorias, em concordância com 0 conjunto de categorias desenvolvido por Cronin e Overfelt (1994), que inclui: Expectativas, Etiqueta, Ética, Equidade e Avaliação. Em decorrência da não aderência de alguns dados encontrados a esse esquema, foi criada a categoria Motivações, de modo a complementá-lo.

\section{RESULTADOS E DISCUSSÃO}

Esta seção apresenta e discute os resultados utilizando o esquema de categorias derivado das entrevistas.

\subsection{Expectativas}

De modo geral, os pesquisadores entrevistados concordaram que os agradecimentos são utilizados para recompensar aqueles indivíduos e/ou outros atores sociais cujas "contribuições 
menores" não foram suficientes para que eles adquirissem o status de coautor na publicação. As respostas de pesquisadores das Ciências da Saúde e das Ciências Sociais têm um tom similar ao afirmar:

Eu acho que os agradecimentos têm essa conotação de incluir pessoas que, de alguma forma, colaboraram, mas colaboraram de forma indireta com a pesquisa. (CSA11).

Mas tem pessoas que às vezes têm um papel que não é direto no trabalho intelectual que foi feito no artigo [...] mas que merecem reconhecimento. Por exemplo, às vezes a gente mostra pra alguém senior, pra dar uma opinião se naquilo falta alguma coisa ou se tá bem fundamentado, como é que ele veria. Até pra poder antecipar o que um comitê editorial vai dizer. E essas pessoas merecem um crédito nos agradecimentos no final. (CSA10).

Esse agradecimento é [para] alguém que [...] fez uma pergunta, indicou uma bibliografia, indicou alguma falha, mas ela não exerceu efetivamente, colocou a mão na massa [...]. As contribuições dos agradecimentos são passagens pontuais, ou apontamentos que são dados com relação à estruturação do texto, à indicação de algum método quantitativo [...]. (CSO5).

Outro entrevistado, vinculado às Ciências Agrárias, oferece um ponto de vista particular ao alegar que:

Eventualmente, a gente agradece a uma pessoa que nem tem interesse em ser autor. A contribuição dela é por outros motivos [...] ela nem cogitaria o fato de ser autor [do artigo], que é o caso, por exemplo, de pessoas que permitem acesso a instalações ou a áreas. (CAG3).

Essas contribuições, embora menores, são suficientemente meritórias para serem reconhecidas via agradecimentos, manifestando-se de diversas formas, conforme o tipo de apoio recebido. Segundo o pesquisador CAG1 tais contribuições agradecidas "[...] refletem uma participação bem efetiva de um técnico, o apoio do pessoal de campo em uma estação experimental”, trazendo à tona a importância do suporte destes não apenas na manutenção de experimentos longos, mas também na publicação subsequente dos resultados que são produto das descobertas. Algumas contribuições mínimas explícitas em agradecimentos podem ser particularmente relevantes para superar algum entrave de um trabalho que será publicado, tendo como origem uma eventual explicação teórica de um cálculo, por exemplo. Na fala de um dos pesquisadores do Instituto de Matemática e Estatística, é possível perceber a importância que determinadas contribuições podem ter durante o desenvolvimento de uma investigação sem, no entanto, justificar uma coautoria, pois representam tão só um "pacto pequeno" entre colegas:

Então, eu não tive uma contribuição intelectual para 0 artigo, eu não contribuí com a experiência, eu não contribuí com dados, eu não contribuí com nada. Eu só ajudei ele a entender a experiência, com um modelo teórico que ele mesmo tinha feito [...]. Então, a minha contribuição nesse caso era mínima, pra mim, um agradecimento tá de ótimo tamanho. (CEX7). 
Em análise dos depoimentos dos entrevistados, percebe-se que a inclusão de agradecimentos em artigos para manifestar gratidão pelo apoio recebido durante o andamento das pesquisas é uma prática comum no processo de comunicação científica, podendo variar o tipo e a intensidade conforme a área. Nesse sentido, alguns pesquisadores da Agronomia explicam que incluir um agradecimento para os donos das áreas ou fazendas nas quais os experimentos são realizados é uma prática comum de alguns grupos de pesquisa da Faculdade, representando uma forma de "sensibilizar a pessoa" (CAG1) e/ou de demonstrar afetivamente a importância da sua contribuição. 0 pesquisador CAG3 complementa que na área de Agronomia também é comum agradecer a contribuição dos "técnicos de laboratório que auxiliam na criação de organismos [...]". Mesmo que não tenham efetivamente uma participação intelectual, eles têm uma participação importante na pesquisa do ponto de vista de serviço. 0 depoimento do pesquisador CAG3 remete à questão de como a conjunção das trajetórias dos atores (pesquisadores e técnicos de laboratório) pertencentes a um mesmo grupo de trabalho constitui uma hierarquia de posições administrativas, estando diretamente ligada ao papel que cada um deles desempenha no processo de produção científica (LATOUR; WOOLGAR, 1997).

A partir das evidências comuns identificadas nas falas dos entrevistados, os agradecimentos em artigos podem ser considerados vestígios de interação entre os agentes envolvidos na pesquisa, representando relações de colaboração e de dependência mútua em termos de recursos e suporte (KNORR-CETINA, 1982), um meio socialmente aceito de recompensar dívidas intelectuais ou materiais para colegas e outros atores sociais (CRONIN; OVERFELT, 1994) e uma forma de socialização entre membros de um campo científico que compartilham o mesmo paradigma (KUHN, 1997).

Em concordância com a sistemática proposta por Cronin e Overfelt (1994), buscou-se também identificar nos depoimentos dos entrevistados por área, ações que evidenciassem o significado social da prática dos agradecimentos em questões inerentes ao processo de comunicação científica, neste caso, relacionadas com: (i) compartilhamento de conhecimento, (ii) conexões intelectuais e (iii) disputas pela autoria.

Em relação ao compartilhamento de conhecimento, observou-se no depoimento de um dos pesquisadores das Ciências Agrárias a importância da colaboração em termos dos benefícios que ela proporciona, sendo que o compartilhamento e transferência de habilidades, técnicas e conhecimentos parece ser um componente fundamental para a viabilização das investigações científicas: 
No âmbito da pesquisa colaborativa, estabelecida dentro dos colégios invisíveis e retratada nos agradecimentos, pôde-se ter um panorama de como o "companheirismo" intelectual (KATZ; MARTIN, 1997) acontece em diferentes áreas, criando redes de contatos fortalecidas pela comunicação informal. Os depoimentos dados por um pesquisador da Faculdade de Ciências Econômicas e por outro do Instituto de Matemática e Estatística exemplificam a questão das conexões intelectuais:

A pessoa às vezes me dá uma ideia, às vezes até num congresso, e daí eu agradeço, eu digo: 'Olha essa sugestão foi do fulano de tal'. (CSO6).

Teve o PV, que é um colega nosso, ele veio até aqui, deu uma conferência e eu disse assim, mais ou menos entendi o que ele dizia e aí eu falei assim: 'Olha, tem um paper meu que faz uma coisa que não é bem isso, mas talvez pudesse ser útil'. Aí ele pegou, leu e viu que, realmente, aquilo que eu tinha dito não era igual, mas aquela ideia podia ser utilizada, aí ele utilizou e me agradeceu. (CEX8).

0 fato é que a eficiência da comunicação informal e a troca de ideias e experiências científicas no interior dos colégios invisíveis podem definir, na maior parte dos casos, o rumo e estratégia das pesquisas em andamento (PRICE; BEAVER, 1966).

Disputas pela autoria ocorrem também no campo científico, definido como uma estrutura dotada de leis próprias, na qual transcorrem as lutas e concorrências pelo monopólio da autoridade e competência científica entre os agentes/instituições que produzem, reproduzem ou difundem a ciência (BOURDIEU, 2004). Alguns vestígios dessas disputas, envolvendo agradecimentos, podem ser evidenciados na fala de um dos pesquisadores vinculados à área da Saúde:

0 projeto já especifica quem serão os autores. Então a gente já recebe um projeto dizendo: 'Olha, é um estudo multicêntrico e vão ser incluídos um, no máximo dois, autores por centro, os demais envolvidos ou os centros que não incluírem o número mínimo [de pacientes] serão colocados como agradecimento'. (CSA11).

Relações de colaboração, envolvendo pesquisas médicas multicêntricas, implicam um maior número de conflitos e negociações pela autoria e reconhecimento, que podem estar influenciados pelo caráter da disciplina e pela estrutura e dinâmica da atividade científica da comunidade em questão (ROA CELIS, 2002).

\subsection{Etiqueta}

De maneira unânime, os pesquisadores entrevistados concordaram que não existem regras ou normas explícitas que determinem 0 ato de agradecer nas publicações científicas. 0 pesquisador CEX8, do Instituto de Matemática e Estatística, enfatizou a inexistência dessas normas ao afirmar que 
os agradecimentos são atos "voluntários" ou "espontâneos". Em concordância com Cronin e Overfelt (1994), o pesquisador CS05, da Faculdade de Ciências Econômicas, caracterizou o comportamento do agradecimento como um ato de "cortesia profissional".

A fala do pesquisador CSA12 segue na mesma direção ao expressar que os agradecimentos representam "demonstrações de gentileza" para aqueles pares e/ou outros atores sociais que tiveram uma participação importante durante a pesquisa que terminou em publicação. Essa posição corrobora as evidências identificadas nas opiniões dos pesquisadores da UFSCar sobre a prática de agradecimentos (HAYASHI, 2018).

Por outro lado, alguns entrevistados como o pesquisador CAG3, da Faculdade de Agronomia, e o pesquisador CSO6, da Faculdade de Ciências Econômicas, afirmaram que a prática do agradecimento no processo de comunicação científica, reconhecendo 0 valor da contribuição recebida, está mais relacionada com uma "questão ética", uma "questão de honestidade" no interior dos grupos de pesquisa. Dessa forma, o entrevistado confirma a ideia do código implícito de conduta profissional que rege, da mesma maneira do que as citações, os agradecimentos (CRONIN; WEAVER, 1995).

A resposta do pesquisador CEX8, do Instituto de Matemática e Estatística, tem um tom parecido, já que comentou que o ato de agradecer está relacionado mais com uma questão de se sentir em "dívida intelectual" com todos aqueles que de alguma maneira ajudaram a fazer a pesquisa. As evidencias encontradas por Hayashi (2018) nos depoimentos dos pesquisadores da UFSCar parecem corroborar a ideia do código implícito de conduta profissional na prática do agradecimento no processo de comunicação científica, dado que os participantes subscreveram a ideia de serem regidos por "regras" diretamente vinculadas a ele.

As evidências identificadas nos depoimentos dos pesquisadores entrevistados revelam que existem diferentes razões que influenciam o comportamento individual destes e "regulam" as práticas de agradecimento no processo de comunicação científica. Neste estudo, percebe-se que a principal razão para agradecer o apoio recebido durante 0 andamento de uma pesquisa está relacionada com uma exigência institucional. Nesse sentido, houve um consenso quanto à necessidade de inclusão de agradecimentos de natureza financeira nos artigos, uma vez que existe um compromisso prévio com aquelas instituições financiadoras dos projetos de pesquisa (ROA CELIS, 2002) nas diversas áreas.

Sobre 0 assunto, nas respostas dadas por um pesquisador da Faculdade de Agronomia e por outro do Instituto de Matemática e Estatística fica demonstrada a exigência e a "obrigatoriedade" institucional estabelecida para agradecer formalmente às fontes de recursos financeiros nas produções científicas: 
[...] as razões, por exemplo, pra se agradecer a órgãos de fomento são exigências, de modo geral os órgãos de fomento exigem que se faça o agradecimento, e que é justo também, claro, agradecer, então isso é de praxe. (CAG3).

0 que existe é agradecimento a agências financiadoras, quer seja por uma bolsa de produtividade em pesquisa, que é o meu caso, como eu tenho uma bolsa do CNPq pra produzir, eu sou obrigada, o CNPq solicita que, em todas as minhas publicações, apareça um agradecimento a ela [agência financiadora], isso é feito. (CEX9).

Outros entrevistados, como o pesquisador CSO4, da Faculdade de Ciências Econômicas, apresentaram um ponto de vista singular ao entender que a inclusão de agradecimentos por financiamento em publicações não representa uma "obrigatoriedade" e sim uma maneira de atribuir uma relação de institucionalidade entre a agência financiadora e o pesquisador:

[...] eu faço por espontaneidade, ou seja, exigência institucional não é uma exigência [...] é conveniente você estabelecer seu vínculo institucional [...] e continuo colocando 'Pesquisador do CNPq', porque a minha bolsa de produtividade continua em exercício [...]. (CSO4).

0 depoimento do pesquisador CSO4 remete à questão da credibilidade científica, significando que a trajetória acadêmica dele pode representar o retorno formal do investimento na sua formação (LATOUR; WOOLGAR, 1997). A credibilidade científica propicia a obtenção de prestígio acadêmico, uma espécie de name-dropping institucional - "olhem a minha qualificação acadêmica!", "[...] que repousa quase exclusivamente sobre o reconhecimento [...] do conjunto de pares ou da fração mais consagrada dentre eles [...]." (BOURDIEU, 2004, p. 35). Ou seja, ser "Pesquisador do CNPq" é fazer parte de uma elite científica altamente prestigiada na comunidade acadêmica.

Dentre os pesquisadores entrevistados por área, não foram identificadas evidências que representassem práticas de agradecimento baseadas nos requisitos editoriais das revistas científicas para as quais eles submeteram seus trabalhos. Apenas o pesquisador CSA11, das Ciências da Saúde, comentou que, nas pesquisas multicêntricas das quais participa, às vezes, a inclusão de agradecimentos nas publicações é influenciada pelas políticas editoriais de alguns periódicos, já que determinam um número máximo de autores/artigo. Por esse motivo, aqueles centros que tiveram menor participação na pesquisa são recompensados com um agradecimento apenas.

A maioria dos pesquisadores entrevistados se opõe à ideia de ter que solicitar permissão antecipada daqueles a quem eles querem agradecer nas publicações, dado que os agradecimentos representam uma maneira afável de reconhecer 0 valor da contribuição recebida, corroborando as descobertas de Cronin e Overfelt (1994). As evidências identificadas nos depoimentos de um 
pesquisador da Faculdade de Agronomia e de outro do Instituto de Matemática e Estatística justificam essa declaração:

Quando a gente faz a gente acho que interpreta essa questão de agradecer um técnico e tal, a gente interpreta que vai ser encarado de uma forma positiva, então a gente não chega a consultar. (CAG1).

[...] em geral, em Matemática, a gente sempre entende que 0 agradecimento é algo, normalmente uma coisa positiva e dificilmente eu vou pedir uma autorização pra uma pessoa pra fazer algo positivo por ela, não é [...]. (CEX7).

Uma minoria dos entrevistados, eventualmente, procura permissão daquelas pessoas a quem quer manifestar sua gratidão pela contribuição recebida. 0 depoimento de um dos pesquisadores da Faculdade de Agronomia explica essa questão:

Nós podemos colocar você [indivíduos que trabalham com taxonomia e identificam organismos] nos agradecimentos dizendo que você identificou esse grupo pra nós, essa espécie, este grupo ou esta planta? Nesse caso, sim, sempre pedimos a permissão porque a pessoa vai, o nome da pessoa vai tá relacionado à informação que ela deu, então se pede sim a permissão. [...] indiretamente eu to colocando também essa pessoa na responsabilidade do organismo, quer dizer, se tiver um erro, essa pessoa [...]. (CAG3).

As opiniões agrupadas sob a categoria "etiqueta" possibilitaram a compreensão de que os agradecimentos são decorrência da tradição ou hábito do grupo de pesquisa envolvido e servem para demonstrar a gratidão pelas contribuições recebidas (conceituais e/ou materiais) durante a investigação.

\subsection{Motivações}

De modo geral, percebe-se que os pesquisadores entrevistados, inicialmente, costumam agradecer às fontes financiadoras pela obtenção de bolsas e auxílios, dado que, na maioria dos casos, há uma exigência institucional explícita no contrato estabelecido. Em estudos anteriores, tal conduta foi observada por Roa Celis (2002), ao analisar as práticas de agradecimento de pesquisadores das comunidades brasileira e colombiana da Imunologia.

Por outro lado, as evidências identificadas nas respostas dos entrevistados mostram comportamentos de agradecimento diferentes no que diz respeito aos tipos de apoio agradecido de natureza não financeira. Aparentemente, a inclusão de agradecimentos com manifestações de gratidão por apoio conceitual e/ou intelectual (discussão de dados, feedback crítico, pareceres de revisores) recebido em artigos de áreas, cujos níveis de coautoria costumam ser baixos (p. ex. Ciências Sociais e algumas disciplinas das Ciências Exatas como Matemática), parece ser uma prática comum, 
já que foi verificado nos depoimentos dos pesquisadores da Faculdade de Ciências Econômicas e Instituto de Matemática e Estatística, certo hábito para incluir agradecimentos PIC - Peer Interactive Communication (MCCAIN, 1991) - nas suas publicações. Tais constatações levam a refletir sobre como os pesquisadores se organizam e colaboram em rede através das relações informais, destacando a importância da comunicação interativa entre pares e a constituição e/ou fortalecimento dos colégios invisíveis no âmbito da pesquisa colaborativa nessas áreas.

0 fato é que a colaboração informal, originada pela necessidade de troca e discussão crítica de resultados oriundos de descobertas científicas antes de serem publicados, parece ser uma das principais motivações individuais para a inclusão de agradecimentos PIC nas suas publicações. As evidências identificadas nos depoimentos de um pesquisador da Faculdade de Ciências Econômicas e de outro do Instituto de Matemática e Estatística retratam essa prática e expõem, ao mesmo tempo, 0 lado social e colaborativo da pesquisa:

[...] os agradecimentos, como praxe, aos referees dos artigos, ou seja, aos pareceristas, sem a visão crítica e sugestiva dos pareceristas 0 artigo, de repente, não tem uma evolução a ponto de ser publicado. (CSO4).

Realmente, quando as pessoas agradecem alguém em Matemática, é alguém que efetivamente tem contato com aquela pessoa, é alguém com quem você tem algum tipo de familiaridade. Nunca é alguém desconhecido, quer dizer, é alguém que efetivamente entrou em contato com você ou que leu alguma versão do seu artigo e fez algum comentário ou crítica construtiva. (CEX7).

0 apoio técnico/instrumental foi o tipo de agradecimento frequentemente mencionado nos depoimentos dos pesquisadores das Ciências Agrárias e Ciências da Saúde, trazendo à tona importância da contribuição daqueles indivíduos que desempenham o papel de expert no interior dos grupos de pesquisa de áreas com orientação técnica e experimental. A resposta de um dos pesquisadores lotados na Faculdade de Agronomia retrata esse comportamento:

E outra coisa que se agradece muito, no nosso caso, é o pessoal que trabalha com taxonomia, taxonomistas [...] Então, a gente manda os organismos ou manda fotos e eles são identificados. E então essas pessoas recebem agradecimentos, ou plantas, identificação, quem identifica corretamente a planta pra nós [...]. (CAG3).

Contribuições de caráter técnico/instrumental em artigos científicos podem estar relacionadas não apenas com o fornecimento de conhecimentos técnicos, mas também com a possibilidade de acesso e uso de ferramentas, tecnologias, recursos de infraestrutura e instalações (laboratórios). 0 depoimento do pesquisador CSA12, exemplifica essa questão: “[...] e, muitas vezes, [agradecer] os 
técnicos de laboratórios, porque eles, mesmo que seja a rotina, eles fizeram o trabalho de maneira que o teu objetivo fosse atingido, teve o resultado".

As variáveis motivacionais identificadas no comportamento de agradecimento dos diferentes pesquisadores entrevistados por área exteriorizam as diversas formas que a "colaboração invisível" (CRONIN; SHAW; LA BARRE, 2004; DÍAZ-FAES; BORDONS, 2017) pode assumir na ciência, dependendo do tipo de necessidade que a investigação precisa suprir para se materializar, natureza da pesquisa, estrutura e dinâmica da atividade científica (complexidade das interações humanas) e hábito e costumes das comunidades.

Os entrevistados da Faculdade de Ciências Econômicas e Instituto de Matemática e Estatística relataram que comumente são recompensados com agradecimentos pelas suas contribuições conceituais e/ou intelectuais para as pesquisas dos colegas, exibindo, novamente, as redes de colaboração informal que permeiam a atividade científica. A fala de um dos pesquisadores evidencia esse ponto:

[...] se eu me encontro numa situação diferente desse autor, ou seja, se alguém me passa um texto para eu comentar, para eu fazer uma leitura crítica e propositiva, automaticamente os meus colegas, quando estão para publicar o texto, fazem agradecimentos a uma leitura prévia feita por mim. (CSO4).

Opondo-se a essa ideia, os pesquisadores da Faculdade de Agronomia relatam que não é usual receberem manifestações pessoais de gratidão (do tipo PIC) pelo seu aporte, já que a discussão informal faz parte do dia-a-dia dentro dos grupos de pesquisa. Sempre que as suas contribuições, independente do tamanho, forem substancialmente importantes para a investigação, eles adquirirão status de autor nas publicações. Nesse sentido, o pesquisador CAG1 explicou: "[...] discussões de dados e feedback crítico, que a gente faz diariamente, tanto em relação a artigos de outros quanto em relação a artigos nossos. Só que a gente não tem o hábito de agradecer isso". As falas dos entrevistados das Ciências da Saúde percorre o mesmo caminho, com exceção do pesquisador CSA11, que justificou que, eventualmente, em pesquisas multicêntricas, devido a sua colaboração menor, foi gratificado apenas com uma menção nos agradecimentos.

A linha divisória entre as duas classificações, autores e "subautores" ou indivíduos agradecidos, não é universalmente apreciada nem consistentemente aplicada (CRONIN, 2005), sendo que disputas interpretativas são bastante comuns no meio acadêmico (ainda na época atual), a tal ponto de alguns pesquisadores se sentirem desvalorizados pelos seus aportes e "rebaixados" de coautor para indivíduo 
agradecido (CRONIN, 1995). As evidências identificadas no depoimento do pesquisador CEX8, do Instituto de Matemática e Estatística, exemplificam essa questão: "Isso, já me aconteceu uma vez [ser agradecido] que eu tava trabalhando com uma pessoa e, assim, a coisa depois evoluiu e ele entendeu que a minha participação era pequena e fez o paper sozinho".

\section{4 Ética}

Os pesquisadores entrevistados por área foram unânimes ao afirmar que não existem sanções explícitas para aqueles autores que, de maneira eventual, possam ter se esquecido de agradecer formalmente nas suas publicações a contribuição recebida. Nenhum dos entrevistados, inclusive se manifestou claramente a favor da aplicação de sanções para aqueles que desrespeitam o "código implícito de conduta profissional" que rege os agradecimentos (CRONIN; WEAVER, 1995). Somente o pesquisador CAG1, da Faculdade de Agronomia, de maneira superficial, comentou que 0 fato de esquecer, involuntariamente, de agradecer um apoio recebido poder ser entendido como: "[...] uma interpretação negativa do colega por ter sido omitido em determinada contribuição dele". Outros pesquisadores entrevistados como CEX7 sugerem relativizar a questão das sanções para "infratores" (CRONIN; OVERFELT, 1994), ao ponderar que a omissão de agradecimentos na ciência poderia gerar, eventualmente, tão só: "[...] algum mal estar [...]" "[...] alguma pequena briga entre pessoas [...]". 0 pesquisador CS06, das Ciências Econômicas, declarou: "Eu acho que sanção não existe. A sanção que pode existir é tu deixar de ajudar o cara, dizer: Bom, eu não vou mais ajudar o fulano, porque se eu dou ideia, se eu faço não sei o que e o cara ignora depois, eu não vou mais [...]".

De modo geral, em nível de indivíduos agradecidos, as respostas dos entrevistados por área revelaram que a omissão de agradecimentos por contribuições intelectuais e/ou conceituais jamais poderia ser considerado um fator suficientemente agravante a ponto de caracterizar "plágio acadêmico". A ideia de que o plágio é exclusivamente atribuível à autoria, negligenciando citar/referenciar as ideias pertencentes a outra(s) pessoa(s) e inseridas no próprio texto é manifestada no depoimento do pesquisador CEX7, do Instituto de Matemática e Estatística: "0 plágio seria você realmente pegar um trabalho de uma pessoa e aí, de fato evidente, copiar. Bom, aí é um plágio porque você tá pegando exatamente o mesmo método e tá simplesmente fazendo uma transcrição".

Tendo em vista que a dinâmica diária das interações acadêmicas entre colegas e alunos é tão intensa e desestruturada, a impossibilidade prática de registrar e atribuir formalmente a procedência de 
cada contribuição recebida através dos agradecimentos é uma consequência quase inevitável (CRONIN; OVERFELT, 1994). No entanto, a omissão involuntária de agradecimentos por prováveis contribuições recebidas pode promover a discussão no âmbito dos estudos sobre comunicação científica, ao remeter à questão da ética na ciência e ao conceito de criptomnésia, que significa "plágio inconsciente" (MERTON, 1979), por se referir a um pensamento aparentemente criativo de um cientista que pode ter sido baseado em uma leitura ou discussão informal ocorridas no passado, mas que não são lembradas e reconhecidas. Assim, essa ideia passa a ser considerada "nova" e "original" quando, na realidade, ela pode ser "[...] 0 resíduo esquecido do que alguma vez foi lido ou ouvido em algum lugar." (MERTON, 1979, p. 73).

\subsection{Equidade}

Em geral, os pesquisadores das diferentes áreas percebem claramente a diferença entre os tipos de contribuição recebida (coautor vs. indivíduo agradecido) durante suas investigações, reafirmando que os agradecimentos são utilizados apenas para recompensar contribuições menores. As evidências identificadas no depoimento de um dos pesquisadores da Faculdade de Ciências Econômicas, elucida essa questão:

[...] esse agradecimento é alguém que, como o que eu te disse, ela fez uma pergunta, indicou uma bibliografia, indicou alguma falha, mas ela não exerceu efetivamente, colocou a mão na massa, ela possa ter lido assim, feito assim mais apontamentos. Na medida, se essa contribuição, a pessoa pegou o texto, reescreveu, reestimou, pegou algum dado que ele tenha trabalhado, daí geralmente a pessoa passa a ser coautor. (CSO5).

0 que se vislumbra nas respostas dos entrevistados, no entanto, é uma falta de precisão para fixar os limites a partir dos quais uma contribuição recebida merece ser recompensada com um agradecimento ou com uma autoria, trazendo à tona a mesma sensação de dúvida apontada em estudos anteriores (CRONIN; OVERFELT, 1994; CRONIN, 2005; DÍAZ-FAES; BORDONS, 2014; HAYASHI, 2018). 0 fato é que a maneira como uma contribuição intelectual e/ou material vai ser recompensada está condicionada não apenas às interpretações dos pesquisadores (CRONIN; OVERFELT, 1994; CRONIN, 1995), mas também às decisões arbitrárias dos grupos de pesquisa a serem tomadas em situações específicas, envolvendo critérios que determinem o grau de envolvimento de cada participante, interesses pessoais e/ou institucionais, estratégias de publicação, subjetividade etc.

0 depoimento de um dos pesquisadores das Ciências da Saúde exemplifica uma situação na qual uma contribuição presumivelmente "menor" foi recompensada com uma autoria: 
Outra coisa que a vida real mostra, quando uma pessoa é muito senior e ela começa a ter um valor estratégico, porque ela é tão importante que qualquer dedo dela no artigo vai ter vantagem pros autores, às vezes existe isso. Eu me lembro, teve um paper que nós fizemos com aquele cara ali ó, foi prêmio Nobel de Medicina, o S., eu mandei pra ele, era com uma molécula que ele tinha mandado pra mim anos atrás e que nós estávamos trabalhando aqui, e eu tinha que mostrar esses dados pro S. e aí ele olhou e fez alguns comentários. Aí eu disse pra ele assim: 'Olha professor, agradeço seus comentários, mas adoraria ter o senhor como coautor'. Ele disse: 'Ah, eu aceitaria'. Aí ele entrou num paper. Ele fez pouco, mas é um prêmio Nobel de Medicina [...]. Ou seja, ele fez muito pouco na prática, mas puxa ele era uma pessoa tão senior que qualquer frase dele dava um up. (CSA10).

A resposta de um dos pesquisadores das Ciências Exatas ilustra uma situação na qual um pesquisador foi promovido imprevistamente de indivíduo agradecido para coautor, gerando a mesma sensação de imprecisão de interpretação, quando se trata de conceder crédito para uma contribuição, percebida em estudos anteriores (CRONIN; OVERFELT, 1994):

[...] eu me lembro agora que tem um colega meu, o R. E., que ele um dia chegou lá, abriu um paper, tava vendo não sei o que, e tava ele como coautor lá. E ele ficou surpreso que ele tava como coautor [...] aí ele foi falar com 0 autor e 0 autor disse 0 seguinte: 'Não, te lembra, nós conversamos e tu me disse uma coisa lá que foi fundamental pra mim fazer. Foi tão fundamental que eu entendi que tu deverias participar'. (CEX8).

Motivada pela falta de familiaridade dos pesquisadores em geral com as diretrizes do International Committee of Medical Journal Editors (ICMJE), que determinam quem deve ser considerado um autor ou um indivíduo agradecido, a diversidade de percepções acerca do que caracteriza a autoria (MARUŠI冈; BOŠNJAK; JERON囚|囚, 2011) fez com que várias revistas adotassem um sistema mais transparente para garantir o reconhecimento daqueles que realmente colaboraram para a elaboração de um artigo, incluindo uma lista de contribuintes onde a contribuição de cada autor para a pesquisa é explicitamente declarada (WAGER, 2009; DÍAZ-FAES, BORDONS, 2014, MCNUTT et al., 2018). A respeito dessa situação, o pesquisador CSA11 entende que a iniciativa adotada por algumas revistas tem sido uma boa alternativa, mas que ainda determinar autoria (e indivíduo agradecido) em publicações continua sendo um processo muito subjetivo. Para se chegar a essa definição, conforme aponta Hayashi (2018), vários fatores e critérios, não tão claramente definidos pelos pesquisadores, concorrem entre si.

\subsection{Avaliação}

Os entrevistados das Ciências da Saúde, Ciências Exatas e Ciências Sociais se manifestaram desfavoráveis à ideia da utilização dos agradecimentos como indicador de impacto acadêmico (e elaboração de um índice similar ao Science Citation Index Expanded - SCIE) por representarem 
contribuições menores. As questões levantadas pelos entrevistados remetem fielmente às diferenças de valores entre os tipos de influência intelectual (citação vs. agradecimento) que apoiam a produção científica. 0 pesquisador CEX9, do Instituto de Matemática e Estatística, respondeu: “[...] quando você cita um autor significa que você leu aquele trabalho e precisou dele pra dar fundamentação ao seu, então ele contribuiu muito, não é um coautor, mas ele contribuiu. Um agradecimento eu acho que não faz sentido. Não, não tem o mesmo peso".

Alguns pesquisadores, como CSO6, se opõem à criação de um índice de agradecimento que permita recompensar quantitativamente o mérito daqueles indivíduos que são agradecidos nas publicações pelo simples fato de que a influência via agradecimentos é algo difícil de ser mensurado por causa da subjetividade na ciência, ressaltando que a pessoa que tem influência intelectual efetiva sobre um pesquisador sempre aparece "citada" no texto. Na mesma direção, o pesquisador CEX7, considera desnecessária a quantificação, uma vez que poderia aumentar tendenciosamente o número de agradecimentos entre pessoas de um mesmo grupo de pesquisa. 0 pesquisador CSA10 foi categórico ao manifestar que a utilização dos agradecimentos como indicadores de impacto na avaliação de desempenho científico originaria muito mais artificialidade do que vantagens para um pesquisador.

Por outro lado, os três pesquisadores das Ciências Agrárias é abertamente a favor da inclusão dos agradecimentos no "sistema de recompensa acadêmico" (CRONIN, OVERFELT, 1994) por compreenderem que aqueles indivíduos que realizaram contribuições menores (não apenas conceituais e/ou intelectuais) nas pesquisas das quais participaram também merecem ter, de alguma maneira, seu crédito assegurado. Sobre essa questão, um dos pesquisadores fez uma analogia:

[...] existe um jogo que tem do campeonato brasileiro, que eles pontuam, eles dão pontos pros jogadores. [...] o jogador que pontua não é só aquele que faz o gol, ou seja, aquele que publica [...] então tu dar uma assistência pra alguém [fazer o gol ou publicar] também é uma coisa importante. (CAG1).

0 uso de indicadores baseados na contagem de agradecimentos por pessoa poderia causar repercussão no processo de avaliação por pares das revistas, uma vez que possibilitaria estimar quantitativamente a importância do trabalho daqueles pesquisadores agradecidos que atuam na qualidade de revisores ad-hoc. Mas, essa é uma situação complexa já que os avaliadores das revistas são anônimos, ou seja, não têm seus nomes identificados nas submissões realizadas pelos autores. 0 fato é que alguns pesquisadores entrevistados das Ciências Agrárias manifestam certa insatisfação perante a falta de um meio que permita recompensar o trabalho de revisão (a priori, contribuições intelectuais menores) na avaliação de desempenho científico: 
[...] os órgãos de fomento aqui no Brasil não fazem, não reconhecem nada. Se você fez vinte revisões, se você fez uma ou se você não fez nenhuma, isso não tem nenhuma relevância, apesar de custar muito tempo e dedicação, pra fazer uma revisão bem feita. Quando você recebe, principalmente em revistas internacionais, os textos em inglês, isso demanda muito mais tempo porque você não só corrige a parte técnica ou a metodologia de trabalho, mas também o próprio texto. (CAG2).

0 pesquisador CAG3 acrescenta que a criação de um índice de agradecimentos, utilizado como indicador de impacto acadêmico, seria uma grande ideia, pois constituiria uma forma de recompensar o trabalho daqueles indivíduos que, mesmo não sendo autores, tiveram uma participação significativa na pesquisa. Esse entrevistado explica: "[...] o exemplo que eu dou pros taxonomistas que são pessoas, pra nós, muito importantes, eles não chegam a fazer parte como coautores porque eles não participaram de todo o trabalho, mas eles são essenciais pro nosso trabalho".

Particularmente, em pesquisas multicêntricas, o índice poderia ser uma saída interessante, pois permitiria recompensar também o mérito daqueles que, por causa das políticas editoriais das revistas que limitam o número de autores/artigo, tiveram seus nomes mencionados apenas nos agradecimentos. A resposta de um dos pesquisadores de Medicina se alinha com essa questão:

[...] por mais que eu não tenha conseguido incluir X pacientes por características, talvez epidemiológicas minhas, eu me envolvi com aquela pesquisa, eu autorizei ela no meu centro aqui, eu busquei incluir pacientes, eu gastei uma determinada energia que talvez pudesse ter, de fato, uma recompensa, não tanto quanto aqueles que incluíram o número necessário, mas, talvez pudesse. (CSA11).

Apesar das demandas reais de alguns entrevistados, o uso de indicadores baseados em agradecimentos para avaliação do desempenho acadêmico dentro de um sistema de recompensa não parece ser um objetivo imediato (DÍAZ-FAES; BORDONS, 2017). Ainda, é preciso que algumas ações sejam tomadas tanto pelas (i) bases de dados (em particular Web of Science - WoS): padronização dos nomes dos indivíduos e instituições agradecidas, cobertura completa dos agradecimentos (por período, tipologia documentária, idioma e índice) quanto pelos (ii) periódicos: editores devem estabelecer subseções para diferentes tipos de dados (financiamento, conflito de interesses, apoio técnico, conceitual etc.), facilitando o processamento automático de captura das informações (DÍAZ-FAES; BORDONS, 2014, 2017).

\section{CONSIDERAÇÕES FINAIS}

Em geral, foi possível compreender através dos resultados sobre percepções e comportamentos de agradecimento que, na atividade científica, os pesquisadores usam agradecimentos para recompensar 
contribuições menores, manifestando-se de diversas maneiras conforme o tipo de apoio recebido. A inclusão de agradecimentos em artigos para demonstrar gratidão e recompensar os pares e outros atores sociais é uma prática comum no processo de comunicação científica, podendo exteriorizar formas não tradicionais de colaboração e influência intelectual.

Quando se trata de uma contribuição material do tipo financeiro, a principal razão para agradecer está relacionada com uma exigência institucional. Ante a falta de regras formais que determinem 0 ato de agradecer nas publicações, agradecimentos para indivíduos por contribuições conceituais e/ou intelectuais (pares, revisores ad-hoc, seminaristas etc.) ou materiais (técnicos de laboratório etc.) é decorrência da tradição ou hábito de cada grupo de pesquisa em particular, estando associado a uma questão ética e de conduta profissional.

As evidências encontradas nas falas dos pesquisadores revelam comportamentos de agradecimentos diferentes entre as áreas. A preferência de manifestações de gratidão por apoio intelectual em Ciências Sociais e Ciências Exatas (Matemática) mostra o papel que os colégios invisíveis assumem no âmbito da pesquisa colaborativa. 0 hábito de incluir agradecimentos por apoio técnico/instrumental em Ciências Agrárias e Ciências da Saúde revela laços de interdependência entre pesquisadores e técnicos (de laboratório, de campo, taxonomistas etc.) nas áreas experimentais.

A pesquisa vislumbrou uma falta de precisão por parte dos entrevistados para fixar os limites a partir dos quais uma contribuição merece ser recompensada com um agradecimento ou com uma coautoria, podendo estar condicionado não só a interpretações individuais, mas também a decisões arbitrárias oportunamente tomadas pelos grupos. A falta de regras formais, ao mesmo tempo, impossibilita a criação e aplicação de sanções para aqueles casos que omitiram agradecer as contribuições recebidas. Tratados no processo de comunicação científica como indicadores de influência intelectual (CRONIN, 1991), a maioria dos entrevistados, no entanto, se manifestou contrário à inclusão dos agradecimentos no sistema de avaliação acadêmico.

Os resultados deste estudo sobre percepções e comportamentos de agradecimento são considerados relevantes e confiáveis e podem promover a realização de novas pesquisas, através de entrevistas com pesquisadores de outras áreas e filiados a outras universidades, que aprofundem a compreensão sobre o significado social dos agradecimentos no processo de comunicação científica, levando em consideração a escassa presença da temática na literatura nacional. 


\section{REFERÊNCIAS}

ACADEMIC RANKING OF WORLD UNIVERSITIES - ARWU. Academic Ranking of World Universities

2017. 2017. Disponível em: http://www.shanghairanking.com/ARWU2017.html. Acesso em: 03 mar. 2018.

BEN-ARI, Eyal. On acknowledgements in ethnographies. Journal of Anthropological Research, v. 43, n. 1, p. 63-84, 1987.

BOURDIEU, Pierre. Os usos sociais da ciência: por uma sociologia clínica do campo científico. São Paulo: Editora UNESP, 2004.

CRONIN, Blaise. Let the credits roll: a preliminary examination of the role played by mentors and trusted assessors in disciplinary formation. Journal of Documentation, v. 47, n. 3, p. 227-239, 1991.

CRONIN, Blaise. The scholar's courtesy: the role of acknowledgement in the primary communication process. London: Taylor Graham, 1995.

CRONIN, Blaise. The hand of science: academic writing and its rewards. Lanham: Scarecrow Press, 2005. $214 \mathrm{p}$.

CRONIN, Blaise; MCKENZIE, Gail; RUBIO, Lourdes. The norms of acknowledgement in four humanities and social sciences disciplines. Journal of Documentation, v. 49, n. 1, p. 1-102, mar. 1993.

CRONIN, Blaise; MCKENZIE, Gail; STIFFLER, Michael. Patterns of acknowledgement. Journal of Documentation, v. 48, n. 2, p. 107-253, jun. 1992.

CRONIN, Blaise; OVERFELT, Kara. The scholar's courtesy: a survey of acknowledgement behaviour. Journal of Documentation, v. 50, n. 3, p. 165-196, 1994.

CRONIN, Blaise; SHAW, Debora; LA BARRE, Kathryn. A cast of thousands: co-authorship and subauthorship collaboration in the twentieth century as manifested in the scholarly journal literature of Psychology and Philosophy. Journal of the Association for Information Science and Technology, v. 54, n. 9, p. 855-871, jul. 2003.

CRONIN, Blaise; SHAW, Debora; LA BARRE, Kathryn. Visible, less visible, and invisible work: patterns of collaboration in 20th century Chemistry. Journal of the American Society for Information Science and Technology, v. 55, n. 2, p. 160-168, 2004.

CRONIN, Blaise; WEAVER, S. The praxis of acknowledgement: from bibliometrics to influmetrics. Revista Española de Documentación Científica, v. 18, n. 2, p. 172-177, 1995.

DÍAZ-FAES, Adrián Arias; BORDONS, María. Acknowledgments in scientific publications: presence in Spanish science and text patterns across disciplines. Journal of the Association for Information Science and Technology, v. 65, n. 9, p. 1834-1849, 2014.

DÍAZ-FAES, Adrián Arias; BORDONS, María. Making visible the invisible through the analysis of acknowledgements in the humanities. Aslib Journal of Information Management, v. 69, n. 5, p. 576590, 2017. 
HAYASHI, Maria Cristina Piumbato Innocentini. Agradecimentos em artigos científicos: o ponto de vista de pesquisadores. Prisma.com, n. 37, p. 55-70, 2018.

HAYASHI, Maria Cristina Piumbato Innocentini; BELLO, Suzelei Faria. Presença dos agradecimentos em um periódico da área de Saúde. Em Questão, Porto Alegre, v. 20, n. 3, Edição Especial, p. 166193, 2014.

KATZ, J. Sylvan; MARTIN, Ben R. What is research collaboration? Research Policy, Amsterdam, n. 26, p. 1-18, 1997.

KNORR-CETINA, Karin D. Scientific communities or transepistemic arenas of research? A critique of quasi-economic models of science. Social Studies of Science, v. 12, n. 1, p. 101-130, 1982.

KUHN, Thomas S. A estrutura das revoluções científicas. São Paulo: Perspectiva, 1997.

LATOUR, Bruno; WOOLGAR, Steve. A vida de laboratório: a produção dos fatos científicos. Rio de Janeiro: Relume Dumará, 1997.

MACKINTOSH, Kenneth Henry. Acknowledgement patterns in sociology. 1972. Tese (Doutorado) University of Oregon, Oregon, 1972.

MCCAIN, Katherine W. Communication, competition, and secrecy: the production and dissemination of research-related information in Genetics. Science, Technology, \& Human Values, v. 16, n. 4, p. 491-516, 1991.

MCNUTT, Marcia K. et al. Transparency in authors' contributions and responsibilities to promote integrity in scientific publication. Proceedings of the National Academy of Sciences, v. 115, n. 11, p. 2557-2560, 2018.

MARUŠIĆ, Ana; BOŠNJAK, Lana; JERONČIĆ, Ana. A systematic review of research on the meaning, ethics and practices of authorship across scholarly disciplines. Plos One, v. 6, n. 9, p. e23477, 2011.

MERTON, Robert K. A ambivalência sociológica: e outros ensaios. Rio de Janeiro: Zahar Editores, 1979.

PATEL, Narsi. Collaboration in the professional growth of American Sociology. Social Science Information, v. 12, n. 6, p. 77-92, 1973.

RANKING UNIVERSITÁRIO FOLHA - RUF. Ranking de universidades. 2019. Disponível em: https:// ruf.folha.uol.com.br/2019/ranking-de-universidades/principal/. Acesso em: 02 abr. 2020.

ROA CELIS, Adriana. A dinâmica da comunidade científica na produção do conhecimento: um estudo da imunologia no Brasil e na Colômbia. 2002. 235 f. Tese (Doutorado) - Instituto de Geociências, Universidade Estadual de Campinas, Campinas, 2002.

SALAGER-MEYER, Françoise; ARIZA, María Ángeles Alcaraz; BERBESí, Maryelis Pabón. "Backstage solidarity" in Spanish and English written medical research papers: publication context and the acknowledgment paratext. Journal of the American Society for Information Science and Technology, v. 60, n. 2, p. 307-317, 2009. 
PRICE, Derek J. de Solla; BEAVER, Donald de B. Collaboration in an invisible college. American Psychologist, Washington, v. 21, n. 11, p. 1011-1018, 1966.

WAGER, Elizabeth. Recognition, reward and responsibility: why the authorship of scientific papers matters. Maturitas, v. 62, n. 2, p. 109-112, 2009. 